\title{
El delito de trata de personas, crimen de lesa humanidad: análisis desde la óptica de la reciente jurisprudencia de la Corte Interamericana de Derechos Humanos
}

The crime of trafficking in persons, crime against humanity: analysis from the best of the recent jurisprudence of the Inter-American Court of Human Rights

O crime de tráfico de pessoas, crime contra a humanidade: Análise sob a perspectiva da recente jurisprudência da Corte Interamericana de Direitos Humanos

Le crime de traite des personnes, crime contre l'humanité: analyse du point de vue de la jurisprudence récente de la Cour interaméricaine des Droits de l'Homme

\section{María Fernanda García ${ }^{1}$ Universidad Nacional de La Plata}

Revista Derechos en Acción

Año 3/NNo 8 Invierno 2018, 455-476

DOI: https://doi.org/10.24215/25251678e192

ORCID: https://orcid.org/0000-0002-3197-2625

Recibido: 15/06/2018

Recibido con modificaciones: 30/06/2018

Aprobado: 19/08/2018

Resumen: El presente artículo pretende realizar un análisis respecto de las consideraciones efectuadas por la Corte Interamericana de Derechos Humanos relativas al fenómeno del trabajo esclavo y al delito de trata de

\footnotetext{
1 Abogada. Maestranda en Derechos Humanos (Facultad de Ciencias Jurídicas y Sociales. UNLP). mfernandagarciacampos@gmail.com
} 
personas con fines de explotación, su vínculo con aquella esfera central de derechos que conforman el jus cogens, y su categorización como crímenes de lesa humanidad, así como las implicancias que esto tiene en el tratamiento de casos a la luz del instituto de la prescripción. El punto de partida para dicho análisis lo constituye la sentencia dictada por la Corte en el caso "Trabajadores de la Hacienda Brasil Verde vs. Brasil" (20 de octubre de 2016), primera ocasión en que se pronuncia respecto del trabajo esclavo, en tanto fenómeno conglobante del trabajo forzoso, el sometimiento a servidumbre y la trata de personas.

Palabras clave: Trata de personas con fines de explotación. Crímenes de lesa humanidad. Imprescriptibilidad. Estándares interamericanos. Derechos humanos.

Abstract This article's objetctive is to analyze the Inter-American Court of Human Rights'considerations, related to the phenomenon of slave labor, as weel as the crime of trafficking in persons for the purpose of exploitation, its conection with the central field of rights called "jus cogens", and their categorization as crimes against humanity, as well as their implications in the treatment of cases concerning the institute of limitation period.

The starting point in this analysis is made by the decisión of the Court in the case "Workers of Hacienda Brasil Verde vs. Brazil "(October 20, 2016), which is the first time the Court decides with regards to slave labor as an embracing phenomenon of forced labor, submission to servitude and human trafficking.

Key words: Trafficking in persons for the purpose of exploitation. Crimes against humanity. Imprescriptibility. International standards. Human rights.

Resumo: Este artigo pretende analisar as considerações feitas pela Corte Interamericana de Direitos Humanos sobre o fenômeno do trabalho escravo e o crime de tráfico de pessoas com fins de exploração, sua articulação com aquela esfera central de direitos que compõe o jus cogens, e sua categorização como crimes contra a humanidade, bem como as implicações que isso tem no tratamento de casos à visão do instituto de prescrição. 0 ponto de partida para essa análise é a sentença proferida pelo Tribunal no caso "Trabalhadores da Fazenda Brasil Verde vs. Brasil 
“(20 de outubro de 2016), a primeira ocasião em que se pronúncia a respeito do trabalho escravo, como um fenômeno abarcante de trabalho forçado, a submissão à servidão e ao tráfico de pessoas.

Palavras-chave: Tráfico de pessoas - exploração - contra a humanidade

- Direitos humanos

Résumé: L'objective de cette travail est d'analyser les considérations de la Cour Interaméricaine des Droits de I'homme, concernant le phénomène du travail forcé et le crime de traite des personnes avec l'objective d'exploitation, son lien avec le sphère centrale de droits qu'on appelle le "jus cogens", et sa catégorisation comme crime contre I'humanité, ainsi que ses implications dans le traitement des affaires liés a l'institut de la prescription.

Le point de départ de cette analyse est constitué par la sentence de la Cour dans l'affaire "Les travailleurs de la Hacienda Brasil Verde vs. Brésil "(20 octobre 2016), qui a eté la première fois que le tribunaux s'est prononcé à propos du travail forcé, en tant que phénomène inclusif du travail forcé, de la soumission à la servitude et de la traite des personnes.

Mot-clés: traite des personnes - exploitation - Crime contre l'humanité - Droits de l'Homme

\section{Introducción al caso}

El presente artículo pretende realizar un análisis respecto de las consideraciones efectuadas por la Corte Interamericana de Derechos Humanos (en adelante "la Corte") relativas al fenómeno del trabajo esclavo y al delito de trata de personas con fines de explotación, su vínculo con aquella esfera central de derechos que conforman el jus cogens, y su categorización como crímenes de lesa humanidad, así como las implicancias que esto tiene en el tratamiento de casos a la luz del instituto de la prescripción.

El punto de partida para dicho análisis lo constituye la sentencia dictada por la Corte en el caso "Trabajadores de la Hacienda Brasil Verde vs. Brasil" (20 de octubre de 2016), 
primera ocasión en que se pronuncia respecto del trabajo esclavo, en tanto fenómeno conglobante del trabajo forzoso, el sometimiento a servidumbre y la trata de personas.

En dicha oportunidad, se declaró al Estado de Brasil responsable de la violación del artículo 6 punto 1 de la Convención Americana de Derechos Humanos (en adelante "la Convención) ${ }^{2}$, en relación a 84 trabajadores y 1 trabajadora de la "Hacienda Brasil Verde".

Asimismo, se dijo que el Estado había incumplido con los estándares internacionales que fija la Convención en la materia -segundo punto del artículo 6-, en cuanto a que, en los casos en que en el ordenamiento penal de un país exista la pena privativa de libertad acompañada de trabajos forzoso, dicho trabajo no debe afectar a la dignidad ni a la capacidad física e intelectual del recluido.

Para ello la Corte acudió a la figura de crimen de lesa humanidad bajo la cual encuadró los graves crímenes cometidos, aplicándole en consecuencia el instituto de la imprescriptibilidad y habilitando de este modo la posibilidad de su estudio y juzgamiento.

El análisis de la responsabilidad del Estado, en tanto principal obligado de velar por el efectivo goce de los derechos y garantías por parte de las personas sujetas a su jurisdicción, junto con la gravedad y complejidad de los delitos involucrados, es lo que evidenció la afectación de normas del jus cogens que determinó la consideración de crímenes de lesa humanidad aquellos cometidos en la "Hacienda Brasil Verde".

\section{I.a. Los hechos}

En el presente caso se sometió a consideración de la Corte la situación de decenas de trabajadores que permanecieron

\footnotetext{
2 El artículo 6.1 de la Convención dispone: Nadie puede ser sometido a esclavitud o servidumbre, y tanto éstas, como la trata de esclavos y la trata de mujeres están prohibidas en todas sus formas.
} 
trabajando en la "Hacienda Brasil Verde" en condiciones inhumanas y degradantes ${ }^{3}$.

En dicha hacienda, ubicada en el Estado de Pará, al norte de Brasil, eran acogidas personas que habían sido captadas en estados vecinos -Maranhão, Tocantins, Piauí- y transportadas durante varios días en camiones, buses y trenes, para finalmente ser afectadas a la junta de juquira -vegetación autóctona del lugar-, en lugar de a la cría de ganado -actividad por la que era conocido el establecimiento-.

Las condiciones en que permanecieron allí fueron conocidas con exactitud a raíz de los testimonios brindados por dos trabajadores que lograron escapar del lugar en el mes de marzo del año 2000, ante la Policía Federal y el Ministerio de Trabajo.

Si bien estos relatos permitieron conocer la completa dimensión de lo que sucedía en la hacienda, lo cierto es que las sucesivas visitas realizadas casi anualmente durante los años 1988 a 2002 por representantes estatales -agentes de la Policía Federal, personal y funcionarios de la Delegación Regional del Trabajo- brindaron información relativa a la existencia de graves irregularidades vinculadas con violaciones a derechos humanos de los trabajadores.

En particular, se tomó conocimiento de que los trabajadores no tenían posesión de sus cédulas de trabajo-las habían entregado al gerente al llegar al lugar y no se las habían devuelto-; fueron obligados a firmar documentos en blanco; dormían en

3 Cabe mencionar que, junto con la situación de esclavitud de dichos trabajadores, se sometió a consideración de la Corte la desaparición forzada de dos personas -Iron Canuto da Silva y Luis Ferreira da Cruz-, quienes también trabajaban en la hacienda. Si bien el objeto de este trabajo se circunscribe al análisis de lo resuelto por la Corte en relación a las figuras de esclavitud, servidumbre y trata de personas, cabe aquí mencionar la conclusión de la Corte en este punto central en la denuncia. Ello así, el Tribunal sostuvo que del análisis de los hechos no pudo derivar la responsabilidad estatal, concluyendo que "el Estado no es responsable por las alegadas violaciones a los derechos a la personalidad jurídica, vida, integridad y libertad personal, contemplados en los artículos 3, 4, 5 y 7 de la Convención Americana sobre Derechos Humanos, en relación con los derechos del niño, establecidos en el artículo 19 del mismo instrumento, en perjuicio de Iron Canuto da Silva y Luis Ferreira da Cruz, ni de la violación de los artículos 8 y 25 del mismo instrumento en perjuicio de sus familiares" (párr. 434). 
ranchos de madera con techo de lona, sin luz eléctrica y agua corriente; dormían hacinados en hamacas sin poder contar con camas; los sanitarios se encontraban en muy mal estado entre la vegetación de lugar; la alimentación era escasa y de mala calidad; el agua que bebían no era apta para consumo humano; lo que consumían en comestibles les era descontado de sus salarios; debían trabajar durante jornadas de 12 horas con tan sólo un descanso de media hora para almorzar; eran conducidos hasta el lugar de trabajo y recogidos al finalizar la jornada; las tareas eran efectuadas bajo amenazas de los encargados del lugar quienes portaban armas de fuego; en caso de enfermedad -por realizar el trabajo bajo la lluvia o tomar agua contaminadano eran atendidos por médico alguno y se les descontaban los medicamentos de sus jornales.

Estas cuestiones dieron lugar a una primera denuncia efectuada en diciembre de 1988 por la Comisión Pastoral de la Tierra y la Diócesis de Conceição de Araguaia -organismos anexos a la Conferencia Episcopal Brasileña con amplio trabajo social en la zona- junto con familiares de dos trabajadores desaparecidos. En dicha instancia ante la Policía Federal sostuvieron que los trabajadores de la "Hacienda Brasil Verde" se encontraban sometidos a una situación esclavitud y que dos de ellos habían desaparecido.

Luego de una segunda denuncia en enero de 1989 ante el Consejo de Defensa de los Derechos de la Persona Humana del Ministerio de Justicia, en el mes de marzo de 1992 la Procuraduría General de la República decidió dar apertura a un proceso administrativo para investigar los hechos denunciados que habilitaron las sucesivas visitas in loco que se mencionaran.

En el año 1997 se inició un proceso penal contra Raimundo Alves de Rocha - "gato" o empleador de trabajadores rurales- por los delitos de trabajo esclavo, atentado contra la libertad del trabajo y tráfico de trabajadores; contra Antônio Alves Vieira -gerente de la hacienda- por los dos primeros de dichos delitos; y contra João Luiz Quagliato Neto -propietario del establecimiento- por frustración de derechos laborales. 
El proceso fue suspendido respecto del último de ellos en virtud de la baja pena en expectativa que el Código Penal brasilero estipula para el delito endilgado.

Luego de sucesivas declaraciones de incompetencias entre la justicia federal y la estadual, que conllevaron a la dilación del proceso por casi 7 años, en el año 2007 el Superior Tribunal de Justicia indicó que el fuero federal era el pertinente para entender en el asunto.

En el año 2008 el Ministerio Fiscal solicitó que se declarara extinta la acción penal por efecto de la prescripción, criterio receptado por el órgano de justicia que puso fin al proceso en dicho sentido.

Paralelamente, y a raíz de los hechos denunciados por dos trabajadores que lograron escaparse en marzo del año 2000, agentes del Ministerio de Trabajo junto con la Policía Federal ingresaron a la hacienda donde pudieron corroborar los extremos expuestos.

Se generó un procedimiento en el ámbito administrativo en el marco del cual se firmó un acuerdo con los responsables de la hacienda, donde se comprometieron a mejorar las condiciones laborales y de vida de aquellas personas trabajadoras del lugar.

En el año 2002, el Ministerio de Trabajo elaboró un informe donde concluyó que las personas obligadas habían cumplido con el acuerdo, pero lo cierto es que, al momento de dictar sentencia en el caso bajo estudio, la Corte desconocía el resultado final de ese proceso administrativo.

\section{I.b. Actuaciones ante el Sistema Interamericano de Derechos Humanos}

En el año 1998 se decidió llevar el caso a la Comisión Interamericana de Derechos Humanos (en adelante "la Comisión"), concretándose la petición inicial en el mes de noviembre, por parte de la Comisión Pastoral de la Tierra y el Centro por la Justicia y el Derecho Internacional (CEJIL). 
Las conclusiones de la Comisión respecto del caso fueron rotundas: el Estado era responsable internacionalmente por la violación de los derechos contemplados en los artículos 5 (derecho a la integridad física), 6 (prohibición de la esclavitud y servidumbre), 7 (derecho a la libertad personal), 22 (derecho de circulación y residencia), 8 (garantías judiciales) y 25 (protección judicial) de la Convención, en relación con el artículo 1.1 (obligación de los Estados de respetar derechos y libertades) de la misma, en perjuicio de aquellos trabajadores de la "Hacienda Brasil Verde" hallados durante las sucesivas visitas al lugar, por no haber adoptado las medidas necesarias y efectivas para garantizar el efectivo goce de sus derechos sin discriminación alguna.

En particular, la Comisión señaló que la aplicación del instituto de la prescripción al presente caso resultó lesivo del principio de acceso eficaz a la justicia ante casos de violaciones de derechos fundamentales (artículos 8.1 y 25.1 de la Convención), en relación con las obligaciones establecidas en el artículo 1.1 y en el artículo 2 (deber de los Estados de adoptar medidas de derecho interno) de dicho instrumento.

Asimismo, formuló recomendaciones específicas al Estado, entre las cuales se destacan el deber de restituirles a los trabajadores los salarios adeudados por el trabajo realizado y las sumas de dinero retenidas en concepto de alimentación y medicamentos; concretar procesos de investigación relativos a las prácticas de trabajo esclavo de forma imparcial, efectiva y en plazos razonables -en el presente caso, pero en otros también-; implementar políticas públicas -legislativas, judiciales, administrativas- para erradicar el trabajo esclavo en Brasil; velar por el cumplimiento de aquella normativa laboral que prescribe límites temporales a las jornadas laborales, el pago de salarios sobre la estricta base de la igualdad, entre otras; adoptar medidas tendientes a erradicar la discriminación de índole estructural que conlleva al sometimiento a esclavitud y servidumbre.

Luego de otorgarle al Estado brasilero un plazo de dos meses -prorrogados en diez oportunidades- para el cumplimiento de 
dichas recomendaciones y de la ausencia de respuestas del mismo, la Comisión sometió el caso a estudio de la Corte Interamericana, para que, en particular, considerara las acciones y omisiones del Estado a partir del 10 diciembre de 1998, fecha en que Brasil aceptó la competencia contenciosa de dicho Tribunal $^{4}$, incluyendo también aquellos actos de carácter continuo o permanente cuyo perfeccionamiento se extendió con posterioridad a dicha fecha, en virtud de la falta de conformidad estatal con las normas de derecho internacional de los derecho humanos que prohíben el trabajo forzoso, el sometimiento a esclavitud y la trata de personas.

\section{Cuestiones relativas a la obligación de los Estados de garantizar el efectivo goce de derechos}

La Corte tuvo por probado que los hechos sometidos a su estudio fueron cometidos en un contexto local de desigualdad estructural -a lo largo de todo el país, pero por sobre todo en la región norte-, en el que miles de personas son sometidas a prácticas de trabajo esclavo, servidumbre y trata con fines de explotación.

Esta situación generalizada, que trasciende los límites del propio caso, fue el conducto para analizar la responsabilidad del Estado, en tanto principal garante del efectivo goce de derechos por parte de las personas abarcadas por su jurisdicción.

El Tribunal afirmó la existencia de conocimiento estatal respecto de estas prácticas abusivas tanto en la "Hacienda Brasil Verde" -a partir de la información obtenida en las sucesivas fiscalizaciones-, como también en otras zonas del país, constituyendo un fenómeno frecuente que halla su origen en las instaladas prácticas esclavistas de la época de la colonia.

A pesar de dicho conocimiento no se adoptaron las medidas necesarias para prevenirlas y para dar respuestas adecuadas en

\footnotetext{
4 Brasil es Estado Parte de la Convención Americana desde el 25 de septiembre de 1992, pero reconoció la competencia contenciosa de la Corte el 10 de diciembre de 1998.
} 
los casos ya consumados -investigación, juzgamiento y sanción de responsables, acompañamiento y asesoramiento a víctimas, reparaciones adecuadas a las mismas, entre otras-.

Esta actitud pasiva por parte del Estado fue lo que puso de resalto su responsabilidad internacional, ya que, como ha dicho la Corte en innumerables casos, no basta con la mera abstención de violar un derecho, siendo imperiosa la adopción de medidas positivas tendientes a prevenir y subsanar violaciones de derechos que se suscitan en su territorio 5 .

Dentro de esta obligación de garante, el Estado debe impedir que sus agentes, pero también terceros particulares, atenten con los derechos y garantías fundamentales protegidas en las constituciones locales y en tratados internacionales de derechos humanos.

En lo que hace al trabajo forzoso, el delito de trata y el sometimiento a servidumbre, este deber ser encuentra receptado en el artículo 6 de la Convención, en conjunción con el artículo 1.1 del mismo instrumento. De este modo, la primera de dichas normas contempla la prohibición expresa de que ninguna persona sea sometida a dichas condiciones, mientras que la segunda constituye un compromiso de carácter más general por medio del cual los Estados se obligan a respetar los derechos y libertades reconocidos en la Convención y a garantizar su libre y pleno ejercicio por parte de toda persona, sin discriminación alguna.

Esto último es lo que compele al Estado brasilero a adoptar medidas apropiadas y efectivas para erradicar estas prácticas de explotación, es decir, asumir una postura proactiva en los casos concretos en los que deba conocer, pero también de forma preventiva, anticipándose a las violaciones de derechos fundamentales, máxime cuando existe un probado contexto que hace prever futuras transgresiones.

5 Caso de la Masacre de Pueblo Bello vs. Colombia (2006); Gomes Lund y otros (“Guerrilha Do Araguaia") vs. Brasil (2010); Wong Ho Wing Vs. Perú. (2015), entre otros. 
Al respecto la Corte dijo que "la estrategia de prevención debe ser integral, es decir, debe prevenir los factores de riesgo y a la vez fortalecer las instituciones para que puedan proporcionar una respuesta efectiva al fenómeno de la esclavitud contemporánea" (párr. 320).

En esta lógica brindó algunas directivas para llevar adelante dicha tarea, las que se encuentran en sintonía con lo recomendado oportunamente por la Comisión. Entre ellas se pueden mencionar el habilitar instancias efectivas de investigación que permitan identificar, juzgar y sancionar responsables; eliminar legislaciones -sobre todo en materia laboral- que toleren prácticas esclavistas o de explotación; legislar en sentido de prohibir cualquier manifestación de trabajo forzoso, servidumbre o trata de personas; realizar procedimientos administrativos de fiscalización de zonas o regiones alcanzadas en mayor medida por este flagelo; adoptar planes o protocolos de protección y asistencia de víctimas.

Son estas obligaciones de prevención y garantía de ejercicio y goce de derechos humanos lo que le permitió a la Corte entrar a analizar el caso, sin importar que en el mismo hayan actuado terceros particulares, sin la participación de agentes estatales.

Lo que interesó a la Corte es que el Estado, con su falta de diligencia, de algún modo generó las condiciones para que los hechos se sucedieran, para que el sometimiento a trabajo esclavo se produjera y reprodujera a lo largo del tiempo -recordemos que las primeras denuncian en el particular datan del año 1988-.

\section{Crimen de Lesa Humanidad: afectación del jus cogens}

Los crímenes de lesa humanidad, como su nombre lo indica, son aquellos que afectan graves intereses de la humanidad en su totalidad. Entrañan las más graves violaciones de derechos humanos que, por su meridiana importancia, encuentran 
protección en la gran amalgama de tratados y convenciones internacionales de derechos humanos.

En el presente caso, la Corte caracterizó como norma de jus cogens $^{6}$ la prohibición de la esclavitud y las graves violaciones a los derechos de trabajadores de la "Hacienda Brasil Verde" como constitutivos de crímenes de lesa humanidad" ${ }^{7}$. Esta es una de las características más sobresalientes de la sentencia, siendo la primera oportunidad en que la Corte decidió contenciosamente un caso a la luz de las prescripciones del artículo 6 de la Convención ${ }^{8}$.

Para llegar a dicha conclusión no sólo analizó la gravedad de los hechos sometidos bajo su estudio, sino que avanzó aún más, y concluyó que el contexto en el que estaban insertos los trabajadores era un contexto de desigualdad estructural trascendente al propio caso, que colocó a dichos trabajadores, pero también a otras decenas de miles en otros lugares, en dicha situación de explotación extrema.

Es aquí donde radica la responsabilidad del Estado brasilero: la Corte señaló que la falta de acciones positivas estatales para revertir una situación que encuentra sus orígenes en la

6 Retoma el concepto de jus congens de la Convención de Viena del año 1969 que en su artículo 53 lo define como norma o principio del derecho derivado del consenso general de los Estados y de consecuente cumplimiento obligatorio por parte de ellos. Integrante de una categoría privilegiada que no admite excepción ni acuerdo en contrario.

7 Cabe referir que en la sentencia analizada, y a los fines de abordar los hechos de los cuales fueron víctimas los trabajadores de la hacienda, la Corte utiliza los conceptos de trata de personas, sometimiento a servidumbre y a trabajos forzosos como manifestaciones del fenómeno esclavitud, considerando probado en el presente la configuración de todos ellos.

8 Con anterioridad al presente caso, la Corte se ha pronunciado en pocas oportunidades sobre este tipo de delitos, siendo que en las ocasiones donde lo mencionó no ha efectuado mayores profundizaciones en la temática. Así, en el caso Masacres de Río Negro vs. Guatemala (2012), el Tribunal estableció que "la protección contra la esclavitud y servidumbre es una obligación internacional erga omnes, derivada 'de los principios y reglas relativos a los derechos básicos de la persona humana', cuando los Estados tengan conocimiento de un acto constitutivo de esclavitud o servidumbre, en los términos de lo dispuesto por el artículo 6 de la Convención Americana, deben iniciar ex officio la investigación pertinente a efecto de establecer las responsabilidades individuales que correspondan"(párr. 225). Caso Masacres de Ituango vs. Colombia (2006) es otro ejemplo. 
época de la colonia fue lo decisivo para conformar un contexto de tanta desigualdad y asimetría social.

Respecto del desarrollo del concepto de desigualdad estructural que realizó el Tribunal, y en particular el voto razonado del Juez Eduardo Ferrer Mac-Gregor Poisot, se entiende que excede el objetivo del presente trabajo, motivo por el cual sólo se dirá que también constituye de una novedad su inclusión dentro de una sentencia de la Corte Interamericana que por vez primera consideró a la "pobreza" como parte de la prohibición de discriminación por la "posición económica” de las personas.

Ha dicho que conforme el estadio actual de la evolución del derecho internacional de los derechos humanos, el principio fundamental de igualdad y no discriminación se encuentra incluido en la órbita del jus cogens (cf. párr. 416).

A dicha falta de conducta proactiva por parte de Brasil se sumó, en el particular, la ausencia de debida diligencia en la investigación, persecución y castigo de los responsables de la "Hacienda Brasil Verde", así como el debido acompañamiento y asistencia de las víctimas, una vez que desde las esferas del Estado -Policía Federal, Ministerio de Trabajo, Procuraduría General- se tomó conocimiento de lo que acontecía en dicho establecimiento.

Ahora bien, continuando con abordaje atinente a los crímenes de lesa humanidad se puede señalar que el término fue empleado por primera vez en el Estatuto del Tribunal de Núremberg (1945-1946) y reforzado en la estricta necesidad de su persecución y castigo por los Tribunales Penales Internacionales para la ex Yugoslavia (1993) y para Ruanda (1994).

Sólo a modo de ejemplo se puede mencionar un fragmento de la sentencia condenatoria del Tribunal Penal Internacional para la ex Yugoslavia en el caso Prosecutor $v$. Drazen Erdemovic, en la que se dijo que "los crímenes contra la humanidad son serios actos de violencia que dañan a los seres humanos al golpear lo más esencial para ellos: su vida, su libertad, su bienestar físico, su salud y/o su dignidad. Son actos inhumanos 
que por su extensión y gravedad van más allá de los límites de lo tolerable para la comunidad internacional, la que debe necesariamente exigir su castigo. Pero los crímenes contra la humanidad también trascienden al individuo, porque cuando el individuo es agredido, se ataca y se niega a la humanidad toda. Por eso lo que caracteriza esencialmente al crimen contra la humanidad es el concepto de la humanidad como víctima" .

Finalmente, su definición vino a proporcionarla el Estatuto de Roma para la Corte Penal Internacional (2002). En su artículo 7 prescribe:

Se entenderá por crimen de lesa humanidad cualquiera de los actos siguientes cuando se cometa como parte de un ataque generalizado o sistemático contra una población civil y con conocimiento de dicho ataque:

a) Asesinato;

b) Exterminio;

c) Esclavitud;

d) Deportación o traslado forzoso de población;

e) Encarcelación u otra privación grave de la libertad física en violación de normas fundamentales de derecho internacional;

f) Tortura;

g) Violación, esclavitud sexual, prostitución forzada, embarazo forzado, esterilización forzada o cualquier otra forma de violencia sexual de gravedad comparable; b) Persecución de un grupo o colectividad con identidad propia fundada en motivos políticos, raciales, nacionales, étnicos, culturales, religiosos, de género definido en el párrafo 3, $u$ otros motivos universalmente reconocidos como inaceptables con arreglo al derecho internacional, en conexión con cualquier acto mencionado en el

\footnotetext{
9 Tribunal Penal Internacional para la ex Yugoslavia, Caso Prosecutor vs. Drazen Erdemovic, sentencia de 29 de noviembre de 1996, párr. 28. Disponible en http://www.un.org/icty/ cases/jugemindex-e.htm
} 
presente párrafo o con cualquier crimen de la competencia de la Corte;

i) Desaparición forzada de personas;

j) El crimen de apartheid;

k) Otros actos inhumanos de carácter similar que causen intencionalmente grandes sufrimientos o atenten gravemente contra la integridad física o la salud mental o física" (el subrayado me pertenece).

En lo que aquí interesa, dentro de las conductas que se prevén como configurativas de dichos crímenes, se encuentra la esclavitud, definida a continuación, en el inciso c del segundo apartado de dicho artículo: por esclavitud se entenderá el ejercicio de los atributos del derecho de propiedad sobre una persona, o de algunos de ellos, incluido el ejercicio de esos atributos en el tráfico de personas, en particular mujeres y niños.

En la sentencia dictada en el caso Trabajadores de la "Hacienda Brasil Verde", la Corte acudió a estas definiciones a la hora de analizar y precisar los alcances del artículo 6 de la Convención.

En el entendimiento de que la prohibición de la esclavitud, la servidumbre, el trabajo forzoso y las prácticas análogas a la esclavitud son conceptos en permanente evolución, la Corte articuló la letra del Estatuto de Roma con lo previsto en la Convención sobre la Esclavitud adoptada en Ginebra el 25 de septiembre de 1926 y la Convención Suplementaria sobre la Abolición de la Esclavitud de 1956. En la primera de ella se definió la esclavitud como "el estado o condición de un individuo sobre el cual se ejercitan los atributos del derecho de propiedad o algunos de ellos" (artículo 1), mientras que en la segunda se amplió el marco de protección incluyendo dentro de la prohibición absoluta de la esclavitud a instituciones y prácticas análogas a la esclavitud, como lo son la servidumbre por deudas y la servidumbre de la gleba (artículo 1).

Más precisamente, sostuvo: "Este concepto ha evolucionado y ya no se limita a la propiedad sobre la persona. Al respecto, 
la Corte considera que los dos elementos fundamentales para definir una situación como esclavitud son: i) el estado o condición de un individuo y ii) el ejercicio de alguno de los atributos del derecho de propiedad, es decir, que el esclavizador ejerza poder o control sobre la persona esclavizada al punto de anular la personalidad de la víctima" (párr. 269) ${ }^{10}$.

Esta base convencional habilita el tratamiento de estos crímenes como parte de la esfera de graves crímenes contra la humanidad por la afectación de derechos fundamentales a la que conducen: personalidad jurídica del ser humano, integridad personal, libertad personal, dignidad, entre otras (cf. párr. 273) ${ }^{11}$.

Del mismo modo, echó mano a la enumeración de conductas que pueden determinar la existencia de una situación de esclavitud -indicadores- efectuada en una primera instancia por el referido Tribunal Penal Internacional para la ex Yugoslavia, y luego por el Protocolo de las Naciones Unidas para Prevenir, Reprimir y Sancionar la Trata de Personas, Especialmente Mujeres y Niños (Protocolo de Palermo) del año 2000.

Algunas de ellas: restricción o control de la autonomía individual, la libertad de elección o la libertad de movimiento de una persona; ausencia de consentimiento o de libre albedrío de la víctima, o su imposibilidad o irrelevancia debido a la amenaza de uso de la violencia u otras formas de coerción, el miedo de violencia, el engaño o las falsas promesas; abuso de

10 La Corte define los conceptos de "estado o condición" como situación de jure pero también de facto, lo que permite pensar que "no es esencial la existencia de un documento formal o una norma legal para la caracterización de ese fenómeno" (párr. 270).

Hace lo mismo respecto del "ejercicio de alguno de los atributos del derecho de propiedad", que define como "posesión", es decir la "demostración de control de una persona sobre otra", "control ejercido sobre una persona que le restrinja o prive significativamente de su libertad individual, con intención de explotación mediante el uso, la gestión, el beneficio, la transferencia o el despojarse de una persona" (párr. 271).

11 En el apartado 306 de la sentencia, la Corte resaltó el carácter de pluriofensivo del delito de esclavitud, inclinándose por la subsunción de todas estas afectaciones a diversos derechos en la figura del artículo 6 de la Convención. 
poder; la posición de vulnerabilidad de la víctima; explotación; exacción de trabajo o servicios forzosos u obligatorios.

En virtud del empleo de esta suerte de guía, y al verificar la Corte la presencia de estos indicadores en el caso de los trabajadores de la "Hacienda Brasil Verde", fue clara la subsunción bajo la figura de esclavitud y, consecuentemente, de crimen de lesa humanidad.

La principal consecuencia de tipo "procedimental" que se derivó de esta categorización de crímenes de lesa humanidad, fue la posibilidad de que la Corte entendiera en el caso más allá del tiempo transcurrido desde que se cometieron los hechos ${ }^{12}$. De este modo, el Tribunal declaró la imprescriptibilidad de los crímenes cometidos contra 84 trabajadores y 1 trabajadora de la hacienda.

Insistió la Corte en que "la esclavitud es considerada un delito de derecho internacional cuya prohibición tiene estatus de jus cogens", motivo por el cual "la prescripción de la acción penal es inadmisible" (párr. 412).

Para un mayor desarrollo al respecto remitió a lo resuelto con anterioridad en los casos Barrios Altos Vs. Perú (2001) -párr. 41-; Almonacid Arellano vs. Chile (2006) -párr. 110/111-; Trujillo Oroza Vs. Bolivia (2002) -párr. 106- y Albán Cornejo y otros Vs. Ecuador (2007) -párr. 111-, oportunidades en las que se expidió en el sentido de no admitir la invocación de figuras procesales como la prescripción para evadir la obligación de investigar y sancionar esta clase de delitos tan graves.

La propia letra del inciso segundo del artículo 27 de la Convención relativo al núcleo de derechos y garantías respecto de los cuales no rige la suspensión contemplada en el inciso primero, ubica a la prohibición de la esclavitud del artículo 6 dentro de la esfera de los derechos esenciales de la condición humana.

\footnotetext{
12 Recordemos que la Corte entendió respecto de aquellos delitos cometidos con posterioridad a la aceptación de la competencia del Tribunal por parte de Brasil en el año 1998, y que la sentencia analizada en el presente trabajo fue dictada dieciséis años más tarde, en el aก̃o 2016.
} 
Finalmente, selló la discusión: "la Corte considera que la prescripción de los delitos de sometimiento a la condición de esclavo y sus formas análogas es incompatible con la obligación del Estado brasileño de adaptar su normativa interna de acuerdo a los estándares internacionales" (párr. 413).

\section{Consideraciones finales}

A modo de conclusión pueden señalarse algunas ideas centrales que la Corte Interamericana de Derechos Humanos introdujo en la resolución del caso sub examine, las que, más allá de la importancia de su novedad, contribuyen a ampliar el espectro de protección de los derechos y garantías consagrados por la Convención Americana de Derechos Humanos.

El caso "Trabajadores de la Hacienda Brasil Verde" constituye la primera ocasión en la que la Corte, dentro de sus facultades contenciosas, resolvió aplicando el artículo 6 de la Convención.

Para ello precisó los alcances de dicha norma: las conductas que determinan la existencia de esclavitud, sometimiento a servidumbre, trabajos forzosos, trata de personas con fines de explotación; así como el carácter pluriofensivo de estos delitos, por la afección que implican al derecho a la personalidad jurídica del ser humano, a la integridad personal, la libertad personal y a la dignidad.

Analizó el contexto en el que se encontraban las personas sometidas a dichas condiciones de explotación, considerando que se trataba de un contexto de desigualdad histórica y estructural que como tal aumentaba exponencialmente las condiciones de vulnerabilidad y, en consecuencia, las posibilidades de quedar sujetos a dichas prácticas abusivas.

Respecto de este último punto, la Corte sostuvo la responsabilidad del Estado brasilero por su pasividad en la adopción de políticas públicas tendientes a erradicar dicho contexto de desigualdad y discriminación, basado en la pobreza -situación 
económica de ciertos sectores sociales-, que bien podrían constituir respuestas válidas de tipo preventivas para una problemática de dimensiones tan complejas como la analizada aquí.

La gravedad de los delitos reprochados en el presente caso -conocidos por agentes estatales desde las primeras denuncias de fines de 1988 y comienzos de 1989-, en sumatoria con este contexto discriminatorio perpetuado a lo largo del tiempo, hicieron concluir a la Corte de que se trataban de crímenes de lesa humanidad, cuya definición trasciende los límites del propio caso de los trabajadores de la hacienda.

En este punto la Corte utilizó los conceptos contenidos en otros tratados y convenciones internacionales de derechos humanos, con el propósito de dar un abordaje integral a la problemática, dimensionando acabadamente las consecuencias vis-à-vis con las obligaciones de los Estados.

Frente a dicho panorama el Tribunal insistió en un concepto esbozado en todos los casos sometidos a su consideración ${ }^{13}$ : la obligación general de los Estados Parte de la Convención de garantizar el libre y pleno ejercicio de los derechos humanos implica el adecuar su derecho y prácticas internas a las disposiciones de la misma -conforme la manda de artículo 2 de dicho documento-. Ello implica que las medidas adoptadas en el ámbito local -sean legislativas, judiciales o ejecutivas- deben ser efectivas -effet utile-.

De este modo, las medidas deberán tender a suprimir normas y prácticas violatorias de las garantías contempladas en la Convención, pero también a la sanción de normas o el dictado e implementación de prácticas conducentes a garantizar su pleno goce y ejercicio (cf. párr. 410).

En el particular, dicha proactividad que se exige al Estado se encuentra vinculada con la necesidad de concretar canales

13 Casos Velásquez Rodríguez vs. Honduras (1988) -párrs. 166 y 167-; González y otras vs. México (2009) -párr. 236-: Masacre de las Dos Erres vs. Guatemala ( 2009) -párr. 234-; Fernández Ortega y otros vs. México (2011) -párr. 191-; Rosendo Cantú y otra vs. México (2011) -párr. 175-; entre otros. 
efectivos de investigación de los hechos denunciados: diseñando mecanismos de real acceso a la justicia por parte de las personas damnificadas; persiguiendo, juzgando y sancionando a los responsables de estas graves violaciones a los derechos humanos; removiendo obstáculos procedimentales -aplicación de la figura de la prescripción- para que dichas pretensiones no se vean frustradas.

Este deber de investigar ya fue exigido al Estado Brasilero en anteriores oportunidades. Así, en los Casos Garibaldi vs. Brasil (2009) y Gomes Lund y otros ("Guerrilha Do Araguaia") vs. Brasil (2010), la Corte le ha dicho que "el deber de investigar es una obligación de medios y no de resultado, que debe ser asumida por el Estado como un deber jurídico propio y no como una simple formalidad condenada de antemano a ser infructuosa, o como una mera gestión de intereses particulares, que dependa de la iniciativa procesal de las víctimas, de sus familiares o de la aportación privada de elementos probatorios. A la luz de ese deber, una vez que las autoridades estatales tengan conocimiento del hecho, deben iniciar ex officio y sin dilación, una investigación seria, imparcial y efectiva. Esta investigación debe ser realizada por todos los medios legales disponibles y orientarse a la determinación de la verdad." (párrs. 113 y 138, respectivamente).

Respecto de los obstáculos de tipo procedimentales, cabe aquí recordar que la Corte en oportunidades anteriores ha sostenido la inadmisibilidad de disposiciones de amnistía y de prescripción cuando se está ante la necesidad de investigar graves violaciones a los derechos humanos ${ }^{14}$, en la medida en que al obstaculizar el esclarecimiento y la efectiva sanción de los responsables, son contrarias al deber de garantía al que se han comprometido los Estados Parte de la Convención.

Por otro lado, la proactividad reclamada al Estado también entraña la implementación de políticas de asistencia y

\footnotetext{
14 Casos Barrios Altos vs. Perú (2001) -párr. 41-; La Cantuta vs. Perú (2006)-párr. 152-; Masacre de las Dos Erres vs. Guatemala (2009) -párr. 129-.
} 
acompañamiento de víctimas y familiares, a la par de acciones que tiendan al restablecimiento, si es posible, del derecho conculcado y la reparación de los daños producidos ${ }^{15}$.

Finalmente, cabe concluir que el presente caso elevó notoriamente el estándar de protección en la materia bajo estudio al considerar los complejos fenómenos de la esclavitud, el trabajo forzoso y la trata de personas como productos de un contexto de desigualdad estructural, en el que la ausencia de políticas estatales resulta el factor determinante a la hora de su permanencia y profundización a lo largo del tiempo. La gravedad y multiplicidad de los derechos afectados -normas de jus congens-, en suma con esa responsabilidad estatal subyacente, determinaron su categorización como crímenes de lesa humanidad, máxima categoría de lesividad reconocida por los tratados y convenciones internacionales de derechos humanos.

\section{Jurisprudencia utilizada}

1. Albán Cornejo y otros vs. Ecuador (C.I.D.H. - 2007);

2. Almonacid Arellano vs. Chile (C.I.D.H. - 2006);

3. Barrios Altos vs. Perú (C.I.D.H. - 2001);

4. Fernández Ortega y otros vs. México (C.I.D.H. - 2011);

5. Garibaldi vs. Brasil (C.I.D.H. - 2009);

6. Gomes Lund y otros ("Guerrilha Do Araguaia") vs. Brasil (C.I.D.H. - 2010);

7. González y otras vs. México (C.I.D.H. - 2009);

8. Kawas Fernández vs. Honduras (C.I.D.H. - 2009);

9. La Cantuta vs. Perú (C.I.D.H. - 2006);

10. Masacres de Ituango vs. Colombia (C.I.D.H. - 2006);

11. Masacre de las Dos Erres vs. Guatemala (C.I.D.H. - 2009);

12. Masacre de Pueblo Bello vs. Colombia (C.I.D.H. - 2006);

15 En este sentido, los casos Velásquez Rodríguez vs. Honduras (1988) -párrs. 166 y 176 ; Gozález y otras vs. México (2009) -párr. 288-; Ticona Estrada y otros vs. Bolivia (2008) -párr. 78-; Garibaldi vs. Brasil (2009) -párr. 112-; Kawas Fernández vs. Honduras (2009) -párr. 76-. 
13. Masacres de Río Negro vs. Guatemala (C.I.D.H. - 2012),

14. Prosecutor vs. Drazen Erdemovic (T.P.I.Y. - 1996);

15. Rosendo Cantú y otra vs. México (C.I.D.H. - 2011);

16. Ticona Estrada y otros vs. Bolivia (C.I.D.H. - 2008);

17. Trabajadores de la Hacienda Brasil Verde vs. Brasil (C.I.D.H. 2016);

18. Trujillo Oroza Vs. Bolivia (C.I.D.H. - 2002);

19. Velásquez Rodríguez vs. Honduras (C.I.D.H. - 1988);

20. Wong Ho Wing Vs. Perú. (C.I.D.H. - 2015). 